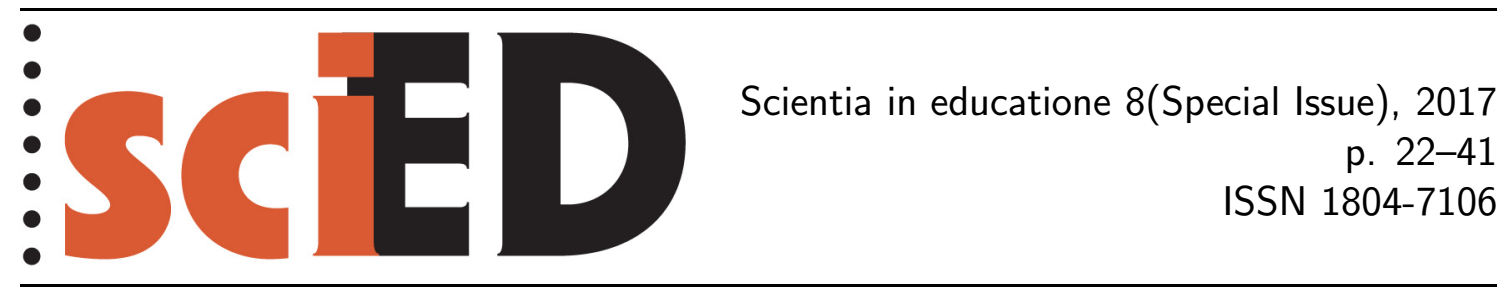

\title{
Sport and Physics
}

\section{Leopold Mathelitsch}

\begin{abstract}
The combination of sport and physics offers several attractive ingredients for teaching physics, at primary, secondary, as well as university level. These cover topics like interdisciplinary teaching, sports activities as physics experiments, video analysis or modeling. A variety of examples are presented that should act as stimulus, accompanied by a list of references that should support the implementation of sport topics into physics teaching.
\end{abstract}

Key words: sport, physics teaching, video analysis, modelling. 


\section{INTRODUCTION}

Physics and sports seem to have not much in common, at least in school teaching, where they are very disconnected subjects: disparate with respect to contents, but also to location, kind of activities or interest of students. Despite this distance, one can find good reasons to bring these two subjects of school education closer to each other: different kinds of sports could serve as examples for applying physical laws; sports activities by students can be seen as physics experiments including quantitative exploration; modern technology offers the possibility to visualize and analyze movements. But this proposal should not be seen as one-directional in that sport comes into the physics class, it should be a challenge for a balanced cooperation. Let's take the location as an example: a physics class can take place in the swimming pool or gym, a sport class can experiment in the physics lab. This implies also a strong collaboration of the teachers: a physics teacher needs the support of the sports teacher while students perform activities; on the other hand, the physics teacher can take over the biomechanical part of sports training. A realization of these goals would lead to a true interdisciplinary teaching, written down in many school curricula around the world, but rarely executed in this sense, also around the world.

The aim of this paper is to illustrate and exemplify the above statements in more detail. The next chapter discusses didactic reasons why a connection of sports and physics could be of mutual benefit to both school subjects. Sometimes teachers claim that they do not find proper material, in particular adapted for use in schools. Therefore special focus is laid on an extensive list of references. The main part of this article, however, consists of a collection of examples that should illustrate and support the theoretical claims.

\section{SPORTS AND PHYSICS}

The link between sports and physics is very important in the professional sport business. In order to improve training techniques and therewith the achievement of athletes, physics enters on several occasions: it plays an important role in the development of new material, it is part of the technological equipment necessary for data taking and analyzing, and it is the basis for biomechanical models trying to understand human performance. Therefore many research institutes have been established, and scientific results are published in corresponding journals.

With regard to school education, the connection of sports and physics is much less obvious. In fact, they represent two subjects that are very often diametric on the scale of attractiveness. Nevertheless, several arguments can be found suggesting to bridge these two sciences even at school level. In the following we will discuss some of them.

\section{VISUALIZATION}

Observation is a discipline in physics education which is not valued and activated to the extent it deserves. Students should learn to observe carefully and also to describe what they see: on the one hand, it is amazing how varying the descriptions of the same action are given by different students; on the other hand, a detailed description leads very often to the question "why", and consequently to an attempt 
for explanation. There could be no better starting point for a topic in physics as when the students ask for an explanation.

Sports actions have one disadvantage in this respect that one cannot observe them easily in reality in a class room. But there exist videos of all kinds of sports actions with the benefit that one can repeat them as often as wanted. And sports actions can be very complex (for example the rotations of a diver off a high board), so that even the task of describing the movement can be demanding to students.

In addition, sports actions can run very fast so that even repetitions do not help in recognizing what is going on. For this reason, slow motion has been used for a long time in analysing such actions. Fortunately, the technological progress made it possible that high-speed cameras are available at such good quality and low price that they became a useful equipment in school labs (Heck \& Uylings, 2010). An example of such visualization is given in the next chapter treating collisions of billiard balls.

\section{VIDEO ANALYSIS}

The next step beyond visualization is a quantitative exploration of an action, very often by video analysis. Several programs for such an analysis have been developed with special emphasis on applications in physics education. Some of them are freely available (Viana, Tracker), some are commercial ones (Logger Pro, Coach). Most of them are very user/student friendly, allowing for tracking certain elements of the action, either by hand or automatically, and enabling easy data taking and processing. Another feature allows for adding information in the video (e.g. velocity or force vectors) leading to a more explanatory presentation (Measure Dynamics).

Video analysis is a very important tool in sports research where simultaneous videos of several cameras can lead to a three-dimensional reconstruction of the event. But even with one camera, results can be obtained of high quality, when the action takes place in a plane like the movement of some sports equipment (ball, spear, ... ). An attractive feature for school physics is the fact that students can take the video by themselves or play the actor (for example executing a penalty in soccer) and they analyze and calculate their own performance (e.g. motion and speed of the ball).

\section{EXPERIMENTS}

Most of the attraction of sports classes is based on activity: students are not only allowed but encouraged to move, to exercise, to compete. In the physics class, experiments are usually the only possibility for physical activity, and this does not happen too often, in general. Experiments with sports actions could be an interesting and challenging combination of activity and quantitative exploration - both for students and teachers. This can be performed in the class room (a simple determination of the force of the own legs or the measurement of the coefficient of restitution for different balls), in the physics lab (measurement of the properties of a tennis racquet) or out of school (in a billiard saloon).

Experiments in the physics lab are often guided by clear descriptions what the students should do with which apparatus. Sports experiments can be posed as very open tasks, the students could suggest what they want to explore, they should propose and design the experiment. For example, several possibilities exist to measure the coefficient of restitution of a ball; the results of different experiments can be compared and the quality and accuracy of the different methods can be discussed. 


\section{MODELS}

Modeling is an important ingredient of scientific research. Physics curricula demand that modeling should also be part of the education of students, even at secondary level (Guttersrud, 2008). A GIREP conference was dedicated entirely to "Modeling in Physics and Physics Education" (van den Berg, Ellermeijer \& Slooten, 2008). Modeling tools are sometimes even implemented in video analysis software (van Buuren, Uylings \& Ellermeijer, 2010).

Working with ideal situations (a mass glides without friction along an inclined plane), the students do not see the value of and necessity for models. Sports actions, in particular when the human body is involved, are very complex. In order to describe and explain them, students see immediately that they have to make approximations, simplifications, and therefore have to work with more or less sophisticated models of the real situation.

\section{INTEREST}

Several studies have shown that physics is not a popular school subject. In a representative study in the province of Styria (Austria) more than one thousand of students aged 10 to 14 were asked which school subjects they like and in which they are interested (Lex \& Gunacker, 1998). The data reveal that the interest is high when the students start with this school type, but that it drops immediately after. The bad message is not only the decrease, but that it happens during the first year of physics teaching.

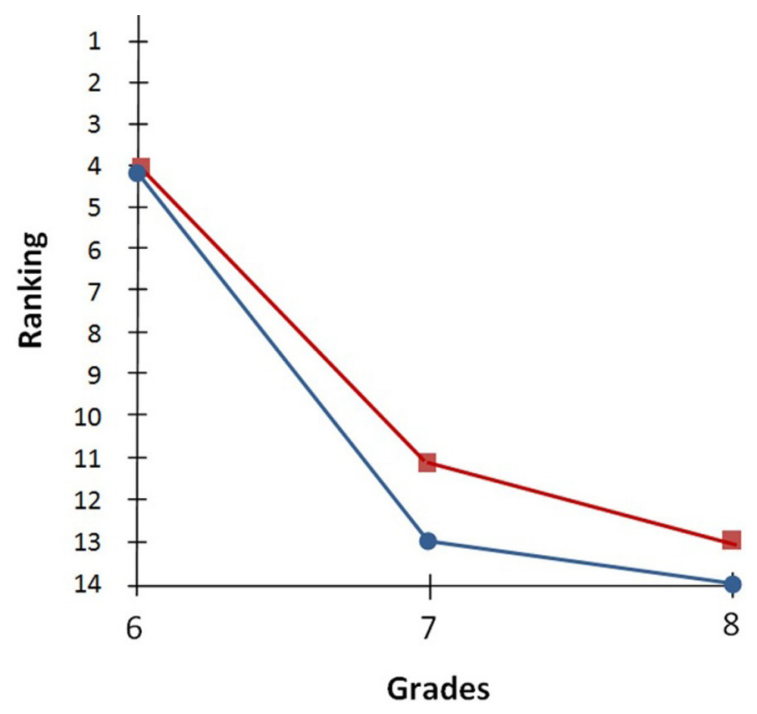

Figure 1: Interest in (blue circles) and popularity of (red squares) the subject physics (Lex \& Gunacker, 1998)

Another study by a German group was much more detailed (Häußler et al., 1996). Figure 2 shows three groups of students, those interested in physics (A), a second group with medium interest (B) and a third one which indicated no interest (C) - this definition is a bit simplified compared to the original article (Häußler et al., 1996). The students were asked in which components of physics their interest lies, in which field they want to learn more: quantitative physics (brown columns), qualitative physics (green), functioning of technical instruments (red), natural phenomena (yellow), and physics and society (blue). The profile of the three groups 


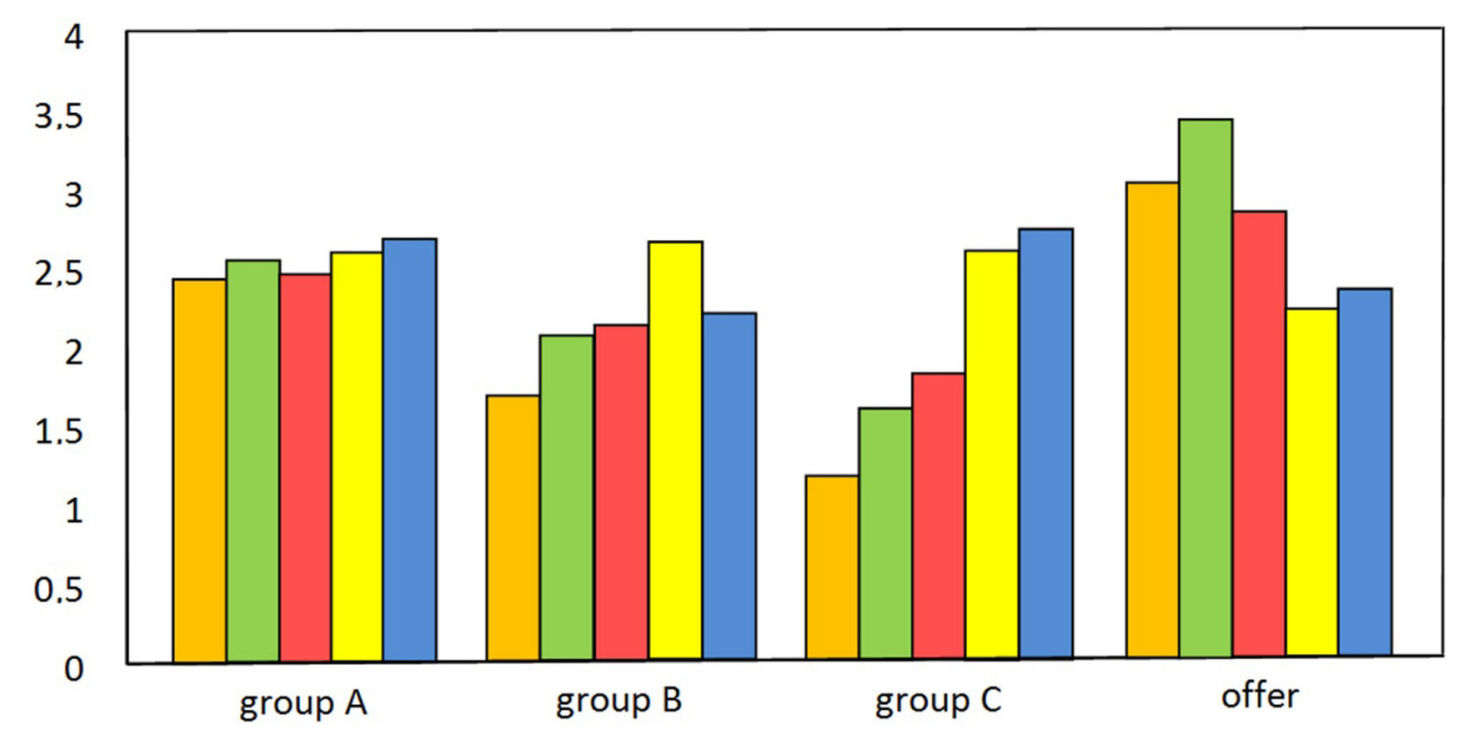

Figure 2: Interest profile of students (description see text) (adapted from Häußler et al., 1996)

is given in the left graphs. And on the very right side the actual offer is shown, as indicated by the students. A discrepancy is obvious and also disturbing. I do not advocate here that the desires of students should be the guidelines for teaching, but, speaking in economic terms, a company is not well advised when it produces against the market (group $\mathrm{B}$ and $\mathrm{C}$ make about 80 percent of the students).

Investigations revealed what particular topic and content are of special interest to students (Trumper, 2006). Not surprisingly, a gender difference shows up: roughly speaking, boys have a tendency to the technological side of physics, whereas girls are interested in those fields that are more related to the human being (biophysics, medicine, society) (Häußler \& Hoffmann, 2000). Sports falls into both of the above categories, again with some differentiation - boys are more fond of soccer, motor sports, girls more of gymnastics, Nordic walking and related activities. But in general, topics of sport are on the positive side of the interest for the majority of students and could therefore serve the purpose to make physics more attractive to them.

\section{LITERATURE}

Literature about the combination of sports and physics can be divided into specific groups. Research papers on the different aspects of biomechanics and related topics fill by far the largest area. I do not even want to try listing the names of journals dedicated to these topics, since they are such a great many. Above all, the articles naturally are so specialized that a transfer to educational purposes is very often difficult to make.

Journals like American Journal of Physics or European Journal of Physics aim at a broader audience, and teachers of physics are an intended target group. The articles therefore give a wider view on a topic. And a noticeable number of articles belong to sports and physics. Therefore a literature research in both journals is a good starting point in looking for profound information on physical explanations of sports topics. A Resource Letter has been compiled in American Journal of Physics with many references to articles and books ordered along sports topics (Frohlich, 
2011). The journal Physics World in 2012 dedicated an entire issue to the topic "Physics and Sport" (Physics World, July 2012).

A gold mine, not only with regard to educational purposes, are books, entitled "Physics and ..." giving a broad but profound view on the sportive and the physical sides of a special kind of sport: "The Physics of Baseball" (Adair, 2002; Cross, 2011), "The Physics of Basketball" (Fontanella, 2006), "The Physics and the Art of Dance" (Laws, 2002), "The Physics of Golf" (Jorgensen, 1999), "Physics of Hockey" (Haché, 2002), "Physics of Sailing" (Kimball, 2010), "Physics of Skiing. Skiing at the Triple Point" (Lind \& Sanders, 1996), "The Science of Soccer" (Wesson, 2002), and similarly "Bicycling Science" (Wilson, 2004), "Gliding for Gold" (Denny, 2011), "The Mathematics of Projectiles in Sport" (de Mestre, 1990), "Golf Balls, Boomerangs and Asteroids" (Kaye, 1996). I apologize for having missed some discipline or book. Equally important are books that give an overview like "The Physics of Sports" (Armenti, 1992), "An Introduction to the Physics of Sports" (Spathopoulos, 2013),"The Dynamics of Sports: Why That's the Way the Ball Bounces" (Griffing, 2000), or "Gold Medal Physics. The Science of Sports" (Goff, 2010).

Less common are articles that are directed mainly to the implementation into physics education at high school level. "The Physics Teacher" or "Physics Education", for example, act as forum for such publications. "Sports Science" (Wiese, 2002) is a booklet dedicated to a young audience. Finally, I would like to point to a special project in the UK called "E-Learning in Physical Science through Sport ELPSS" within the National Teaching Fellowship Scheme (Lambourne, 2014). A collection of so-called reusable learning objects has been developed with a mixture of videos, information and tasks; to my opinion an excellent material on problembased learning applying sport examples.

Because of the readership of this proceedings, a constraint was set on English literature and no material in other languages was included (not even mine).

\section{EXAMPLES}

This chapter contains a collection of examples, correlated only by the combination physics and sports exhibiting the many facets of this topic. Most of the examples have been tested in school practice.

\section{BILLIARD}

"Follow shot" is a special action in billiards: the cue ball hits an object ball centrally and then runs after the object ball. In real time one does not recognize what happens in detail. Watching this action in slow motion, however, gives a clearer picture and students can figure out with the naked eye what's going on (Figure 3). The cue ball is hit on the upper end, therefore it gets speed and rotation in form of top spin (1). Linear momentum is conserved during the collision. Since the two balls have the same mass, the object ball gets the full velocity and the cue ball stops and stays at rest (2). The rotation of the cue ball cannot be transferred to the object ball, because the interaction time is very short and almost no friction works between the balls. Therefore, the rotation stays in the cue ball, it turns on the spot (3). But friction with the fabric causes the cue ball finally to move in the same direction as the object ball (4). 


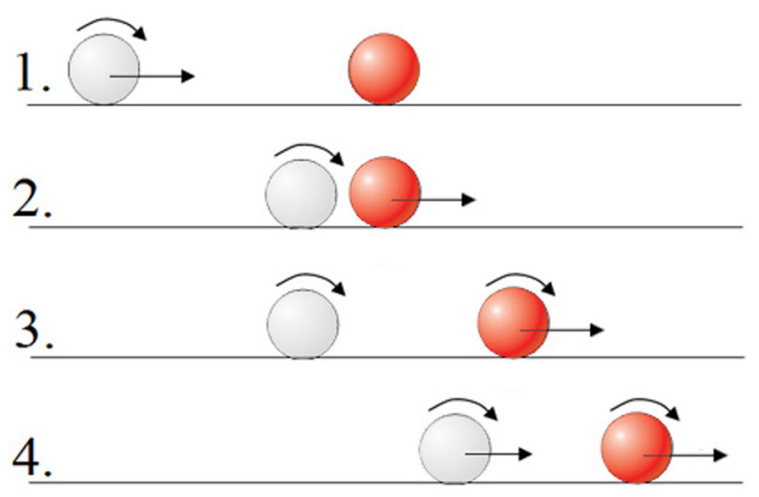

Figure 3: Follow shot (from Mathelitsch \& Thaller, 2008: p. 98)

There exists also the possibility that the cue ball comes back: the player has to hit the ball below the middle and gives it a slice. But this is more difficult, there is the danger to damage the green fabric with the queue and one should not propose this action to students who are playing billiard for the first time.

When the object ball is not hit centrally, the two balls depart always with an angle of 90 degrees between them (Figure 4). Students have problems to believe that this angle is independent of how close to the center or how soft the two balls touch. Basic mathematics should persuade them.

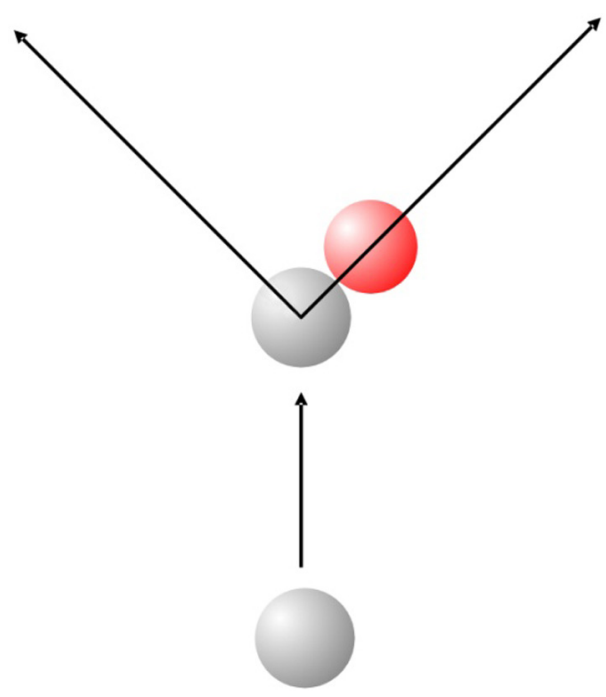

Figure 4: Non-central collision (adapted from Mathelitsch \& Thaller, 2008: p. 99)

Conservation of energy and momentum leads to the following equations

$$
\begin{aligned}
\frac{1}{2} m \cdot V^{2} & =\frac{1}{2} m \cdot v_{1}^{2}+\frac{1}{2} m \cdot v_{2}^{2} \\
m \cdot \vec{V} & =m \cdot \vec{v}_{1}+m \cdot \vec{v}_{2}
\end{aligned}
$$

Division by the mass $m$ and quadrature of the second equations yields

$$
\begin{aligned}
& V^{2}=v_{1}^{2}+v_{2}^{2} \\
& V^{2}=v_{1}^{2}+2 \vec{v}_{1} \cdot \vec{v}_{2}+v_{2}^{2}
\end{aligned}
$$

Subtraction of the two lines leads to the final result

$$
\vec{v}_{1} \cdot \vec{v}_{2}=0 .
$$


That means that the angle between the two velocities after the collision has to and will always be 90 degrees.

This is not only a nice example for physics, it would also fit perfectly into the mathematics class after the introduction of the scalar product.

\section{HIGH JUMP}

An important parameter in jumping wide or high is the force of the legs. This force can be measured and calculated by a simple school experiment, at least approximately (Figure 5). The student stands towards a wall, hands upright, and makes a mark with the tips of the fingers. Then he bends the knee, makes again a mark and jumps as high as possible to put another mark. This is easier said than done, in particular the first part. How deep should one bend the knees? If it is not deep enough or too deep, the jump will not be maximal. Therefore the students first have to find out their optimal bending position.

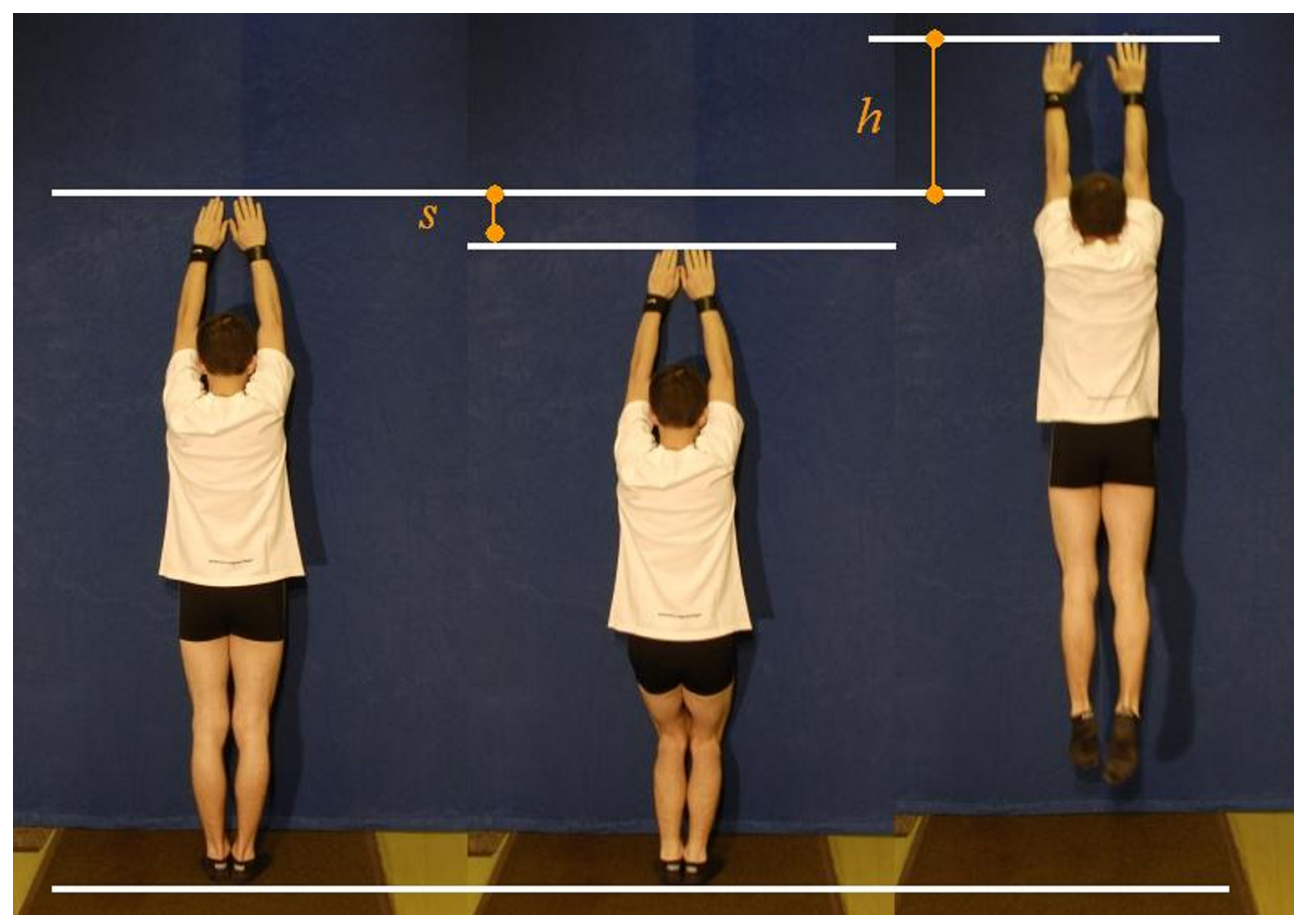

Figure 5: Determining the force of the legs (from Mathelitsch \& Thaller, 2008: p. 57)

The force of the legs $F_{L}$ is applied along the path $s$, the distance between the lowest point and the take off, leading to an energy

$$
E=F_{L} \cdot s
$$

This energy is transferred to potential energy by lifting the body from the lowest to the highest position, i.e. along the distance $s+h$

$$
E=m \cdot g \cdot(s+h)
$$

Equating these equations yields an expression for the force of the legs $F_{L}$.

$$
F_{L}=m \cdot g \cdot \frac{s+h}{s} .
$$


The next example will be somewhat unrealistic, namely jumping on the Moon (Thaller, 2003). How high would one jump on the Moon? I will use this question as an example for applying different models.

The first model is based on the assumption that the jump-off velocity is the same on Earth and on Moon. With a given jump-off velocity $v$, conservation of energy

$$
\frac{1}{2} m \cdot v^{2}=m \cdot g \cdot h
$$

results in a jumping height of

$$
h=\frac{v^{2}}{2 g} .
$$

Since the gravitational force is only one sixth compared to that on Earth, it gives the result

$$
h^{\text {Moon }}=6 \cdot h^{\text {Earth }},
$$

i.e., one jumps six times higher on the Moon as compared to Earth. This calculation and result can be found in many text books.

But one could also imply the assumption that the force of the legs is the same on Earth and on Moon. The accelerating force $F$ is the difference of the force of the legs $F_{L}$ and the gravitational force $F_{G}$

$$
F=m \cdot a=F_{L}-F_{G}
$$

How strong is the force of the legs? A reasonable assumption is two times the own weight, since one can carry another person on the shoulders. By this, the accelerating forces on Earth and on Moon are

$$
F^{\text {Earth }}=m \cdot g, \quad F^{\text {Moon }}=\frac{11}{6} \cdot m \cdot g .
$$

This leads to the fact that the jump-off velocities are not the same on Moon and on Earth

$$
v_{A b}^{\mathrm{Moon}}=\sqrt{\frac{11}{6}} \cdot v_{A b}^{\mathrm{Earth}},
$$

but differ by approximately $50 \%$. Inserting this in the equation for the jumping height from above gives the result

$$
h^{\text {Moon }}=11 \cdot h^{\text {Earth }} .
$$

One jumps eleven times higher on the Moon than on Earth! This is almost twice as much as with the first model. So, which assumption or calculation is correct?

To answer this question we will look at a biomechanical model for jumping (Thaller, 2003). The main ingredient is how a muscle works. Contrary to a common belief a muscle does not function like a spring and would therefore obey a law similar to Hooke's law. Quite differently, the force of a muscle $F_{M}$ is inversely proportional to its speed $v$

$$
F_{M}=\frac{c}{v+b}-a
$$

where $a, b, c$ are parameters that can vary from person to person. Trying to shift a fixed hindrance exerts more force in the muscle as when the hindrance is moving. Applying this so-called Hill equation, a refined calculation yields the following result (Thaller, 2003)

$$
h^{\text {Moon }}=10.5 \cdot h^{\text {Earth }} .
$$


The jumping height on Moon is about 10.5 time as great as on Earth. So, our second model was by far more realistic than the first one.

But men were already on Moon and jumped. Looking at videos, one can recognize only a mingy, a very meager jump. Why didn't John Young go up like hell? First of all, he had some extra weight in his backpack. Secondly, he was afraid of falling. But the main reason was that he was stuck in his space-suit and could barely move.

\section{BOUNCING BALL}

In many ball games, the contact of the ball with some surrounding, racket, floor, wall, basket, concrete layer, is essential. One parameter to characterize such a contact is the so-called coefficient of restitution $e$. It is defined as the ratio of the velocity after the bounce $v_{2}$ relative to the speed before the contact $v_{1}$ :

$$
e=\frac{v_{2}}{v_{1}}
$$

Since the velocity, in the ideal case of only gravitational forces, is connected in a straightforward way with the height, which the ball descends $\left(h_{1}\right)$ and ascends $\left(h_{2}\right)$, the coefficient of restitution can also be expressed in terms of distances

$$
e=\sqrt{\frac{h_{2}}{h_{1}}} .
$$

It is a motivating and for many students also demanding task to determine the coefficient of restitution for several sport balls to a certain accuracy. Since several possibilities can be found to measure the speeds and distances, different groups of students can challenge each other with the quality of their result. A golf ball should not be missing in the assortment of balls, since it is always a surprise for the students how reflective this ball is on a hard surface.

One suggestion by students very often is to use sensors and computers for the determination of the parameters of the movement of the ball. Such an analysis cannot only be used for the measurement of distances and speeds, it can also be extended to a discussion about energies (Turner \& Ellis, 1999). Figs. 6-9 show such a series of investigations.

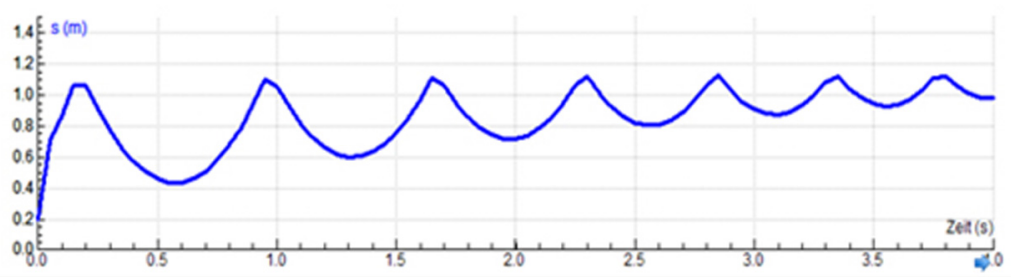

Figure 6: Ball bouncing several times on the floor

The ball is mounted at a certain height and the ball is first located a small distance below the sensor and then falls down to the floor and bounces. The data provide for a diagram like in Figure 6. This figure is often unfamiliar to the students, since it differs from the usual one in text books, where the floor is taken as center of reference. Therefore they have first to change the frame of reference (Figure 7, red curve). 


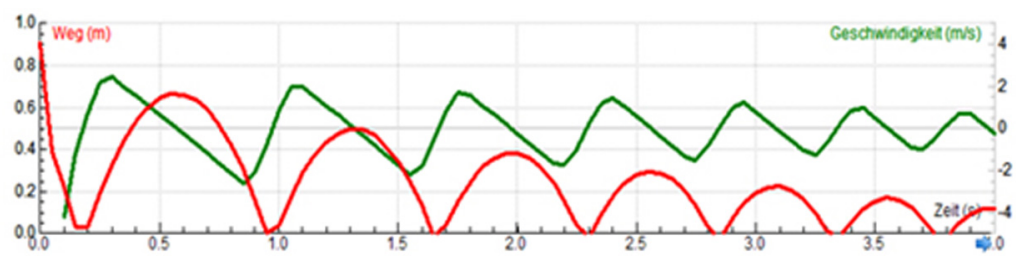

Figure 7: Distance of a bouncing ball relative to the floor (red curve) and corresponding velocity (green curve)

It is a real challenge to the students (sometimes up to college) to determine the velocity out of the data on the distance (Figure 7, green curve). And sometimes one has to help with hints like "At which moments is the speed zero?", "At which is it maximal?", "What does a negative velocity mean?"

The next logical step is to calculate the potential and kinetic energies of the ball (Figure 8). Again, the quadrature of the speed is not always a straightforward task for students.

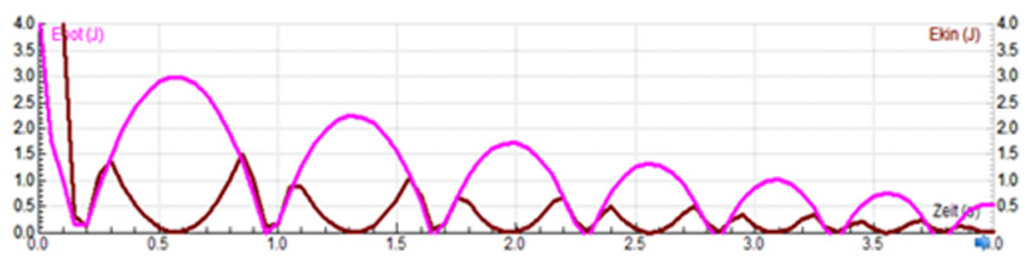

Figure 8: Potential (pink curve) and kinetic energy (brown curve) of the bouncing ball

Addition of both curves gives the total energy of the ball (Figure 9). It is clear that practically no energy is dissipated while the ball is in the air, but that the ball loses almost all of its energy during contact with the floor.

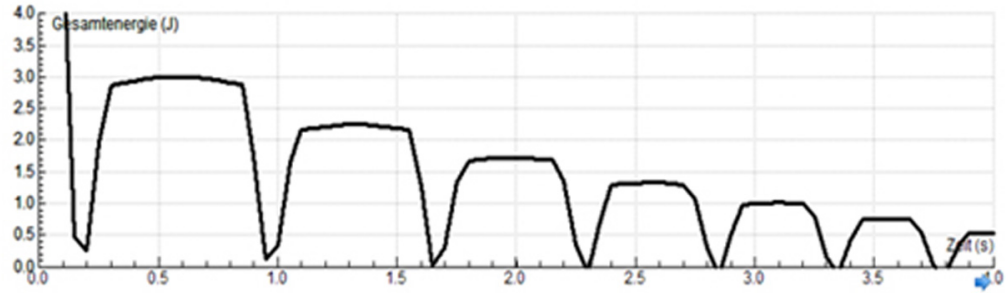

Figure 9: Total energy of the bouncing ball

The figures were produced by a software connected to data analysis (in this case Coach). But I would advise that the students should start and try to make their own figures by hand. Of course it will not be perfect, but it needs an understanding of the kinematic connections that are not always clear to the students.

\section{TENNIS}

In this part I will concentrate on the interaction of a tennis ball with the racket (Duenbostl, Mathelitsch \& Oudin, 1996).

First the elasticity of the frame of a racket was measured. The racket was clamped on the handle and different weights were attached on the frame. Figure 10 shows the deviation of the frame relative to the weight. The relation is nearly a 
straight line, therefore Hooke's law can be applied and the oscillation time $T$ can be calculated

$$
T=2 \pi \sqrt{\frac{m}{k}} .
$$

The constant $k$ can be taken from the slope of the line in Figure $10(k=10 \mathrm{kN} / \mathrm{m})$. But which value should one insert for the mass? This is not an easy question since the racket was clamped on one side - we took half of the mass of the racket $(m=0.16 \mathrm{~kg})$. This leads to an oscillation time of $T_{\text {frame }}=25 \mathrm{~ms}$.

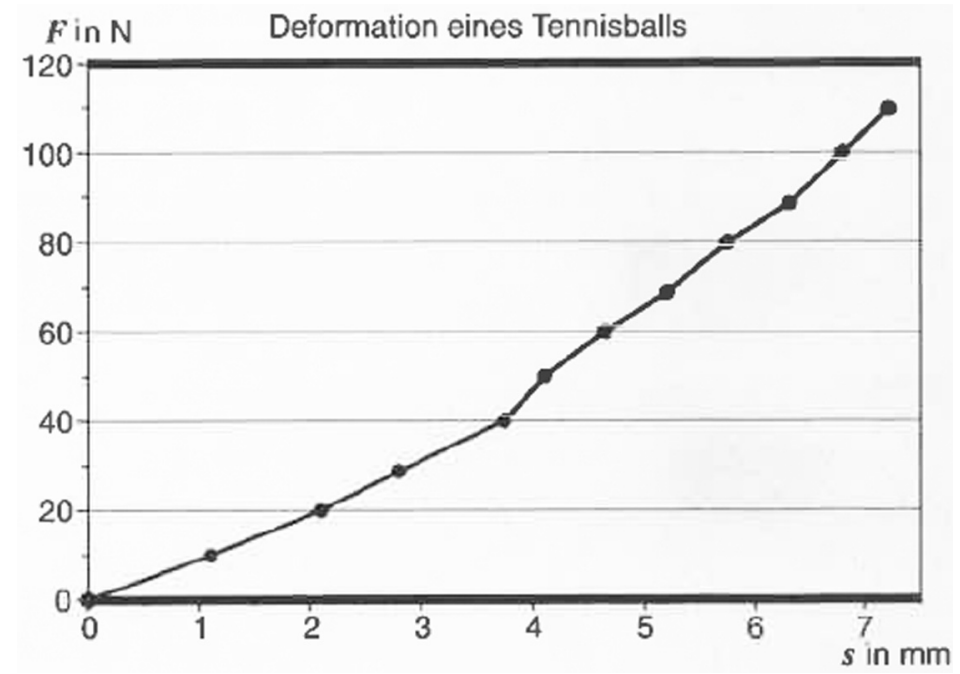

Figure 10: Deviation of the frame of a racket due to different masses attached (from Duenbostl, Mathelitsch \& Oudin, 1996)

But we did not feel safe with this measurement, therefore we applied a different method: Strain gauges were glued to the racket and the resulting voltages were measured. The outcome can be seen in Figure 11. The nice oscillation curve confirms that Hooke's law is valid and also the oscillation time of $T_{\text {frame }}=30 \mathrm{~ms}$ is not too far off the result from before.

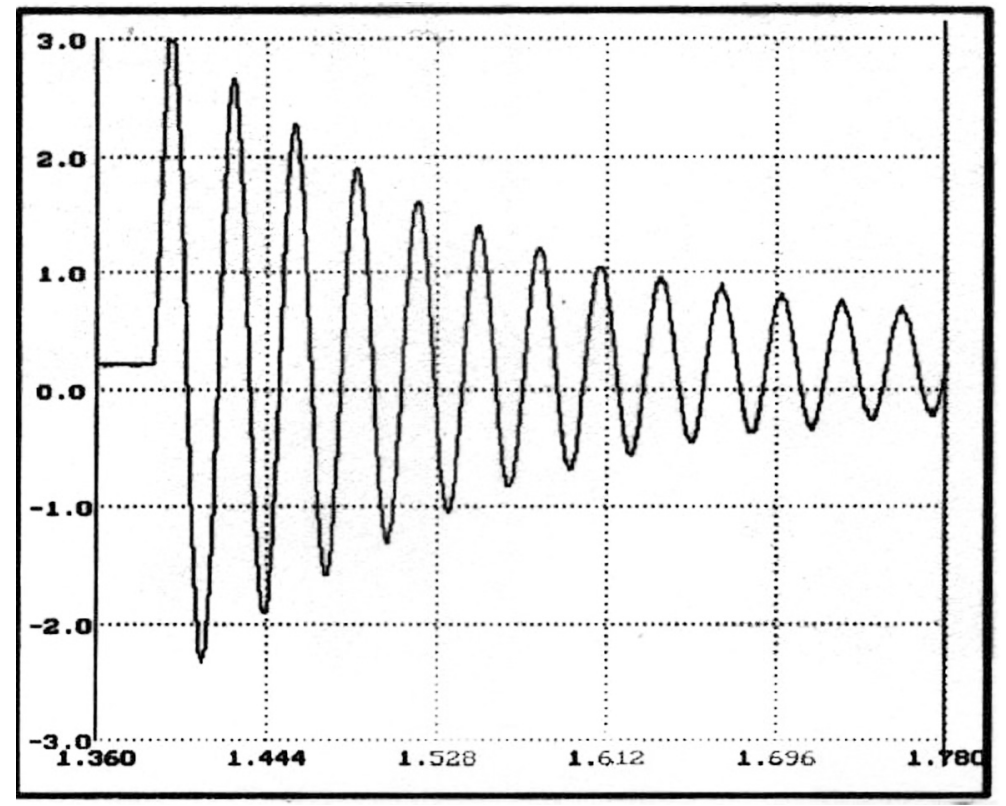

Figure 11: Oscillations of the frame of a racket (from Duenbostl, Mathelitsch \& Oudin, 1996) 
Next we measured the oscillation of the ball. Again we put weight on it and measured the deflection. The data (Figure 12) do not show such a straight line as before, but in first approximation we take it as straight. In this case the mass of the ball is easy to determine $(m=0.058 \mathrm{~kg})$ and with $k=15 \mathrm{kN} / \mathrm{m}$ an oscillation time of $T_{\text {ball }}=12 \mathrm{~ms}$ results.

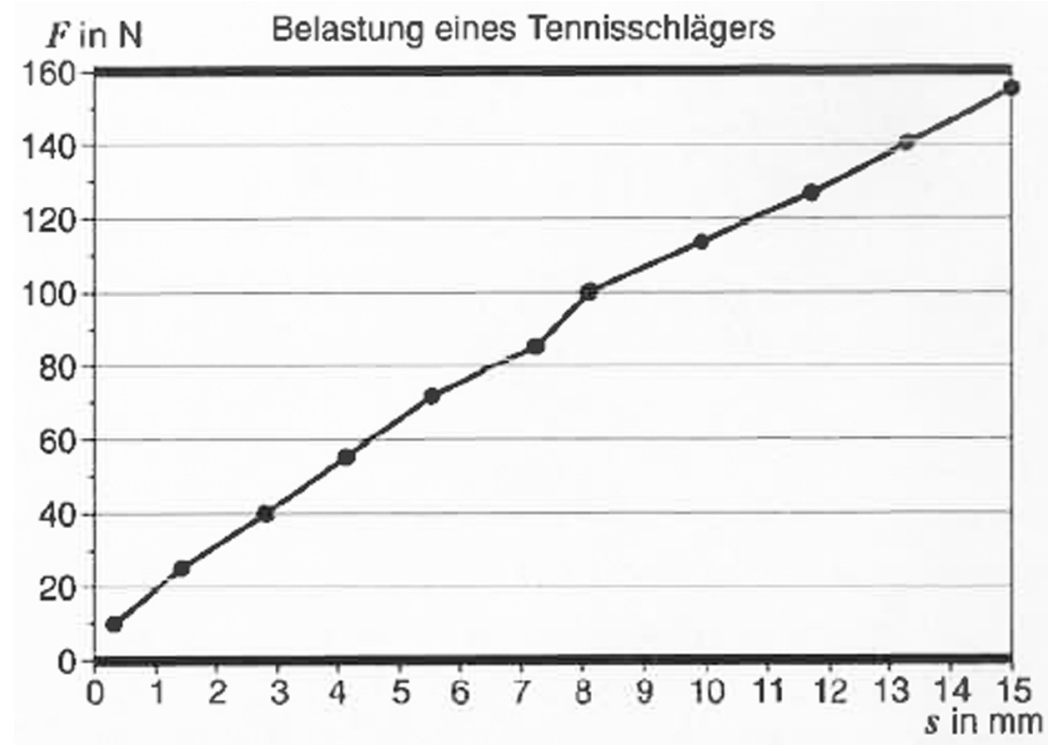

Figure 12: Depression of a ball due to different weights (from Duenbostl, Mathelitsch \& Oudin, 1996)

But this does not fit to the first value: The ball hits the racket, it bends back, then forward, but at that time the ball is already off the racket. The energy of the racket is not transferred to the ball, it is wasted energy. But how does the ball get its great speed? There is another oscillating element involved, the strings. This measurement is not easy since the amplitudes are very small, much smaller than the amplitude of the racket itself. We put a clamp on the racket frame and attached a Hall sensor. A small magnet with little weight was glued to the string. The outcome can be seen in Figure 13.

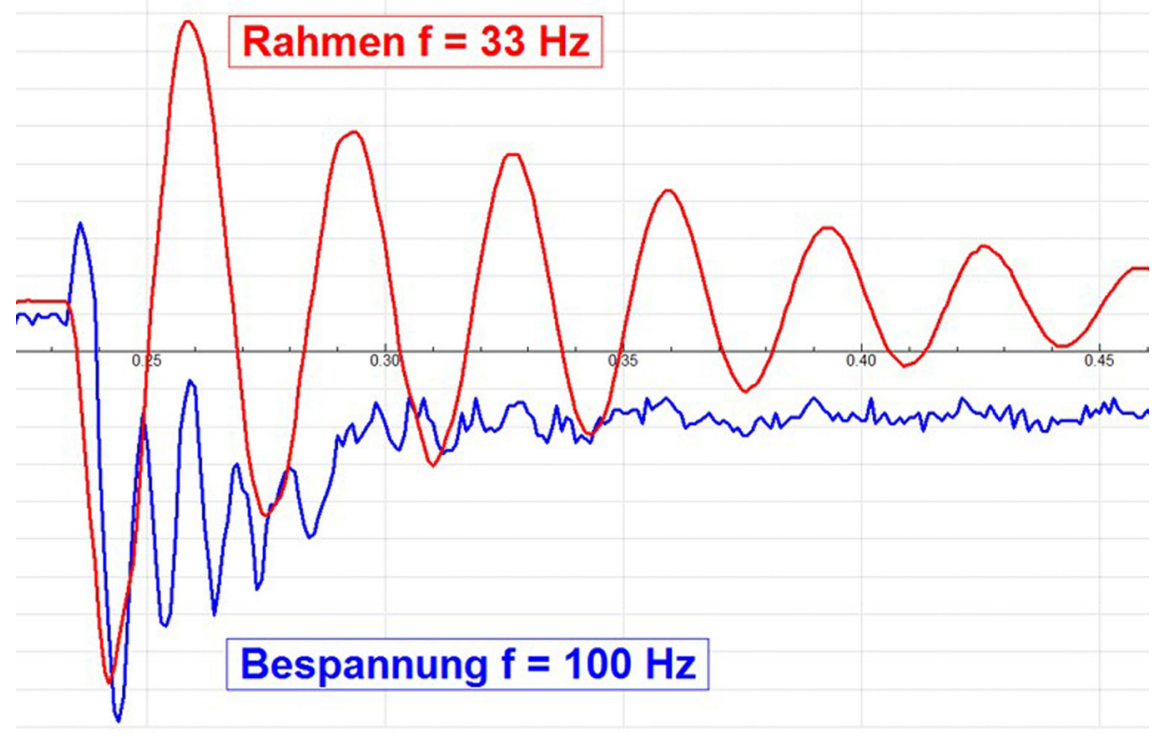

Figure 13: Oscillation of the frame (red curve) and of the strings (blue curve) (adapted from Mathelitsch \& Thaller, 2008: p. 88) 
The oscillation time of the strings of $T_{\text {string }}=10 \mathrm{~ms}$ fits perfectly to the oscillation time of the ball. So, the ball gets most of its energy from the strings, some from the ball itself. The swing of the frame is wasted energy. Therefore the manufacturer tries to make the racket as stiff as possible. In former times several layers of wood were glued together in a refined manner for this purpose. But these rackets had to be small, larger ones would have been too heavy. With new materials, it was possible to make larger rackets, stiff and light.

\section{SOCCER}

An English mathematician, Jack Dowie, has found some statistical correlations in scores of football teams (Dowie, 1981). And then he made an astonishing approach: He compared football to radioactive decay. If a large radioactive probe has a certain decay rate, let's say two decays in one minute, then, in the average, two nuclei will decay per minute. But one does not know how many will decay in the next minute, it could be none, one, two, three, ... But physicists know the probability that zero, one, two, three decays will happen very well - it is given by the Poisson distribution

$$
P_{m}(a)=\frac{a^{m}}{m !} \mathrm{e}^{-a}
$$

$P_{m}(a)$ is the probability that $m$ decays will occur with $a$ being the average decays.

The analogy with soccer goes as follows: A soccer team has a certain strength $a$, for example measured by the average number of goals per match it has scored in the past months. One does not know the score for the next game $m$, but taking the model of Dowie, one can calculate the probability of the number of goals according to the Poisson distribution. Given a strength of two goals, then the percentage for zero goal is $13.5 \%$, for one and two goals it is $27 \%$, for three goals $18 \%$ and so on. And one can determine probabilities for results of matches. If both teams have the same strength of 2 goals per match, the probability for $0: 0$ is $1.8 \%$, it is $7.3 \%$ for $1: 1,2: 1$ and so on. With this model Dowie calculated past results of the English Premier Division, with good agreement. We repeated the calculation with the example of the German Bundesliga (Mathelitsch \& Thaller, 2006), and the result was similarly good, as can be seen in Figure 14. Students can repeat this calculation with their favorite team and can "predict" the result of the next game. This should also create some feeling of statistical results, which is difficult anyway for young and also older people.

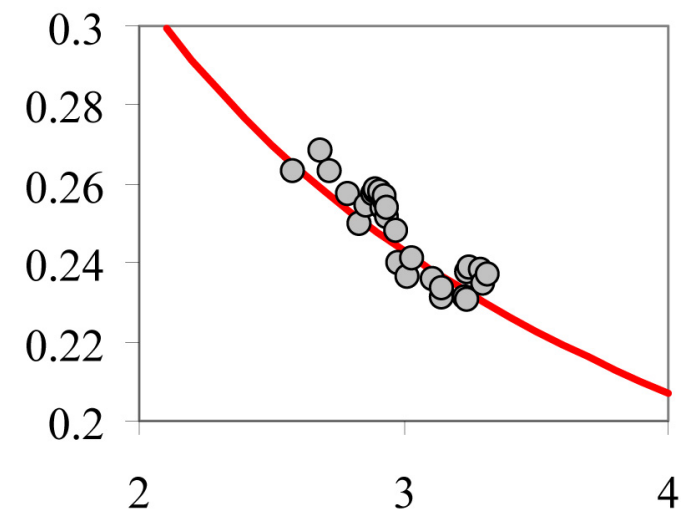

Figure 14: Results of the German Bundesliga (circles) compared to the statistical model (line). (From Mathelitsch, Thaller (2006) modified) 
Students are not always impressed and convinced by the arguments above. Out of experience, the following points count more: One can bet on the results of soccer games (in many countries called Toto). But this resembles very much a typical gamble of luck (Lotto). And it has to be - otherwise experts of soccer would make a fortune by betting. In soccer, a third-class team can win against a first-class team. This does not happen very often in other kinds of sports, and it was calculated that the portion of chance in football is the highest of all kinds of sports-games (BenNaim, Vazquez \& Redner, 2007).

The reason for this strange behavior is simple - it is the low number of goals. Let's assume that team A is twice as strong as team B (such a big difference is very unlikely in a certain league). In this case, the chance for the next goal is $2 / 3$ for team $\mathrm{A}$ and $1 / 3$ for team $\mathrm{B}$. Will there be just one goal in the game, which often happens, the chance for team B to win is $33 \%$, which is not small.

\section{RECORDS}

Very fascinating for athletes, as well as the observing audience, are records, notably world records (Gembris, Taylor \& Suter, 2002). World records will always be broken, even if material, training, ability of athletes would not change (Haake, 2012). Athletes, as all other living creatures, obey a statistical distribution with respect to different features. Figure 15 shows the example of the strength of a muscle; the sample consists of sports students, therefore the distribution is not symmetric. Therefore one does only have to wait long, and one athlete will come up whose features are more on the edge of the distribution — and he/she will break the record. In addition, material and training improve, and therefore new records are even more likely to occur.

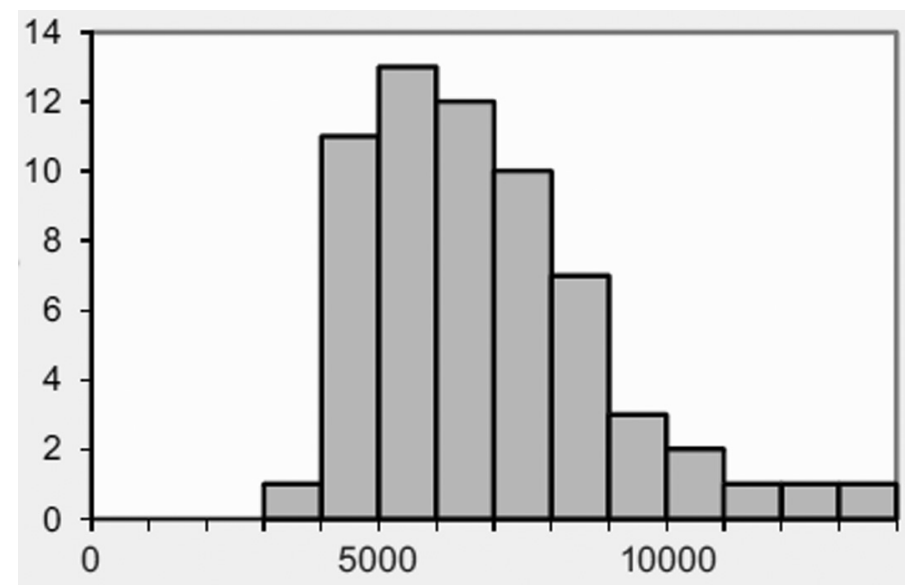

Figure 15: Statistical distribution of the strength of the knee muscle of sports students (from Mathelitsch \& Thaller, 2012)

Many scientists tried to predict how soon a record would be broken, or what will be the ultimate limit a man or woman can achieve. Figure 16 shows the development of the world record in the $100 \mathrm{~m}$ dash. The blue squares represent the data till 2008 , approximated by an unrealistic linear prediction (green line), and a more realistic prediction based on a logistic function (red curve). This curve levels off and leads to an ultimate record value of $9.5 \mathrm{~s}$, indicated by the thinner dashed line. But world records are rare events and therefore a different kind of statistics (like for earth quakes) has to be used (Einmahl \& Magnus, 2008). These models also give an ultimate limit, which is $9.28 \mathrm{~s}$ (thick dashed line). 


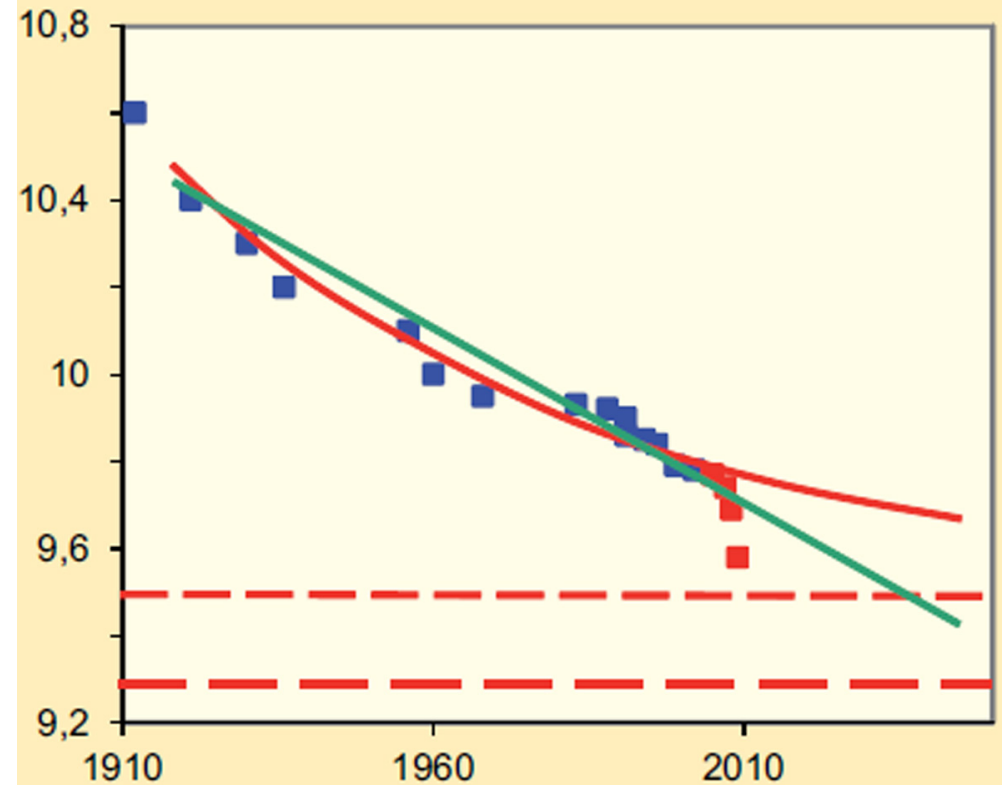

Figure 16: World record of $100 \mathrm{~m}$ dash (men) (from Mathelitsch \& Thaller, 2012). Description in the text

Adding the last records, mainly by Usain Bolt (Hernandez Gomez, Marquina \& Gomez, 2013), gives a strange picture, not seen in any prediction. But it was not only Usain Bolt, several other athletes showed similar improvement of their performance. In the meantime some of them were caught taking not-allowed drugs.

\section{SHOT PUT}

In shot-put we have the rare occasion that two techniques are applied at the same time. Some athletes use the O'Brien or glide technique (Figure 17), some the spin technique (Figure 18).
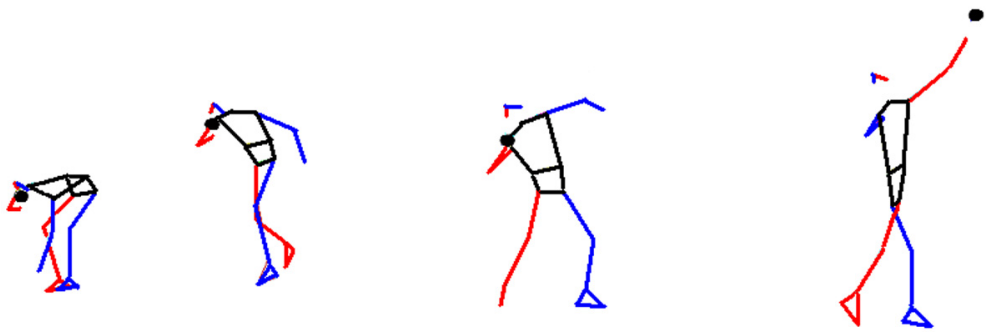

Figure 17: O'Brien or glide technique (from Mathelitsch \& Thaller, 2008: p. 74)
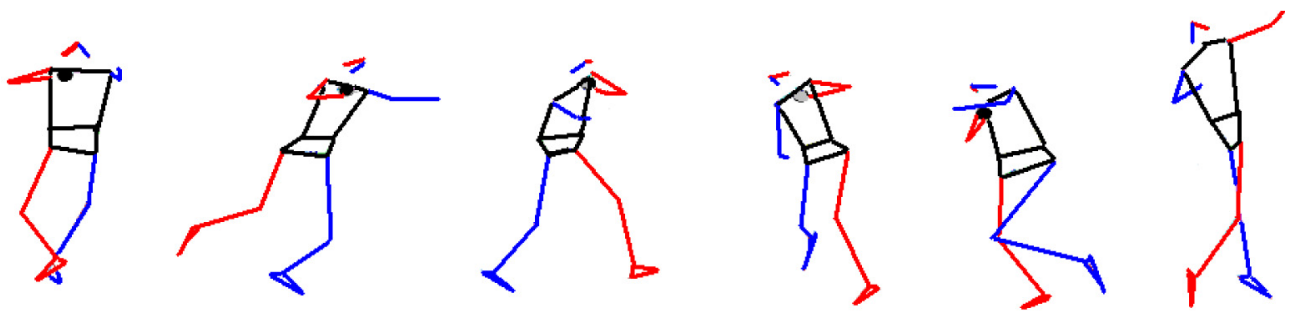

Figure 18: Spin technique (from Mathelitsch \& Thaller, 2008: p. 74) 
But now a new technique came up, here exemplified by the Viennese athlete V. Watzek: a cartwheel technique (Figure 19). Watzek obeys all rules that are not much: She has to stay within the circle, and the ball has to be on the body before the shot. She said that she had better results after a short time of training. Nevertheless, we will not see this technique, because it became forbidden. Official reason: it is not safe enough. V. Watzek claimed that this technique is safer since the movement goes always along the same line in the forward direction. The real reason is that the establishment struck back. Can you imagine that one of the male or female athletes who are the best in shot put could change to this technique?
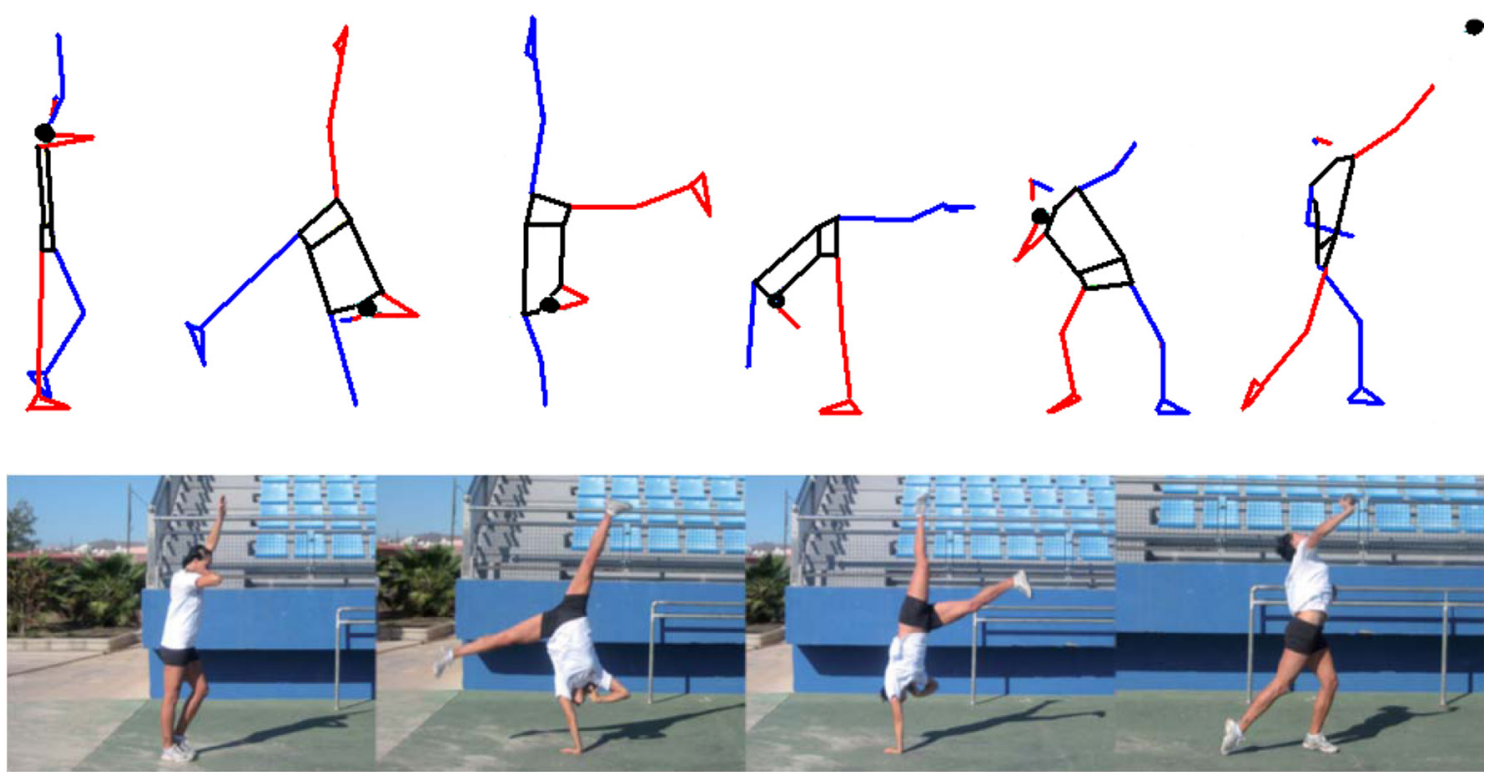

Figure 19: Cartwheel technique (from Mathelitsch \& Thaller, 2008: p. 74, 75)

\section{CONCLUSiOnS}

I hope I could demonstrate with some examples that the combination of sports and physics has a broad range of applications in school physics. With regard to the physics topic it concerns mainly applied mechanics. With regard to pedagogy many aspects can be addressed, experiments, video analysis, project work, interdisciplinary teaching, modeling. An implementation of examples as above has proven to interest also some of those students who were usually not fond of physics. Of course, this topic is not the magic bullet with which physics teaching will escape from the low ranking among the school subjects, but it could help to improve its image from being too abstract and difficult.

\section{ACKNOWLEDGEMENT}

Most of the examples have been developed in close cooperation with Sigrid Thaller, Theodor Duenbostl and Theresia Oudin. I want to thank also Heimo Latal and Gerhard Rath for support in the preparation of this manuscript. 


\section{REFERENCES}

Adair, R. K. (2002). The physics of baseball. New York: Harper Perennial.

American Journal of Physics. Available at http://ajp.dickinson.edu/

Armenti, A. (Ed.). (1992). The physics of sports. New York: American Inst. of Physics.

Ben-Naim, E., Vazquez, F. \& Redner, S. (2007) What is the most competitive sport? J. of the Korean Phys. Soc., 50, 124-126. Available at

http://arxiv.org/abs/physics/0512143

van den Berg, E., Ellermeijer, A. L. \& Slooten, O. (Eds.) (2008). Modelling in physics and physics education. Amsterdam: AMSTEL Inst. Univ. Amsterdam.

van Buuren, O., Uylings, P. \& Ellermeijer, T. (2010). Towards a learning path for computer modelling. In D. Raine,Ch. Hurkett \& L. Rogers (Eds.), Physics community and cooperation. Leicester: Univ. Leicester

Coach. Available at http://cma-science.nl/software/coach6/

Cross, R. (2011). Physics of baseball and softball. New York: Springer.

Denny, M. (2011). Gliding for gold. The physics of winter sports. Baltimore: The Johns Hopkins Univ. Press.

Dowie, J. (1981). Football's failing — the deadly draw. New Scientist, 91, 515-515.

Duenbostl, T., Mathelitsch, L. \& Oudin, T. (1996). Experimente mit dem

Tennisschlaeger. Praxis der Naturwissenschaften-Physik, 45(2), 2-9.

Einmahl, J. H. J. \& Magnus, R. (2008). Records in athletics through extreme-value theory. J. Am. Statist. Ass., 103, 1382-1382.

European Journal of Physics. Available at http://iopscience.iop.org/

Fontanella, J. J. (2006). The physics of basketball. Baltimore: Johns Hopkins Univ. Press.

Frohlich, C. (2011). Resource letter PS-2: Physics of sports. Am J. Phys., 79(6), $565-574$.

Gembris, D., Taylor, J. G. \& Suter, D. (2002). Trends and random fluctuations in athletics. Nature, 417, 506-506.

Goff, J.E. (2010). Gold medal physics: The science of sports. Baltimore: Johns Hopkins Univ. Press.

Griffing, D.F. (2000). The dynamics of sports: Why that's the way the ball bounces.

Dubuque: Kendall Hunt Pub. Comp.

Guttersrud, O. (2008). Mathematical modelling in upper secondary education

[Dissertation thesis]. Oslo: Univ. Oslo ISSN, 1501-7710.

Haake, S. (2012). Material advantage. Physics World, July 2012, 26-26.

Häußler, P. \& Hoffmann, L. (2000). An intervention study to enhance girl's interest, self-concept, and achievements in physics classes. Journal of Research in Science Teaching, 39, 870-888.

Häußler, P., Hoffmann, L., Langeheine, R., Rost, J. \& Sievers, K. (1996). A typology of students' interest in physics and the distribution of gender and age within each type. 
Int. J. Sci. Educ., 20(2), 223-238. Qualitative Unterschiede im Interesse an Physik und Konsequenzen für den Physikunterricht. ZfDN, 2(3), 57-69.

Haché, A. (2002). Physics of hockey. Baltimore: Johns Hopkins Univ. Press.

Heck, A. \& Uylings, P. (2010). In a hurry to work with high-speed video at school. The Physics Teacher, 48, 176-181.

Hernandez Gomez, J. J., Marquina, V. \& Gomez, R. W. (2013). On the performance of Usain Bolt in the $100 \mathrm{~m}$ sprint. Eur. J. Phys., 34, 1227-1233.

Jorgensen, P. T. (1999). The physics of golf. New York: Springer.

Kaye, B. H. (1996). Golf balls, boomerangs and asteroids. Weinheim: VCH.

Kimball, J. (2010). The physics of sailing. Boca Raton: CRC Press.

Laws, K. (2002). Physics and the art of dance. New York: Oxford Univ. Press.

Lambourne, R. (2014) E-Learning in Physical Science Through Sport: Learning objects and their dissemination. In ICPE-EPEC 2013 Conference Proceedings. Prague: MATFYZPRESS. Available at http://www.icpe2013.org/uploads/ICPE-EPEC_2013_ConferenceProceedings.pdf Lex, E. \& Gunacker, E. (1998). Der Physik- und Chemieunterricht aus der Sicht des Schülers. Plus lucis, 98(1), 7-12.

Lind, D. \& Sanders, S.P. (1996). The physics of skiing: Skiing at the triple point. New York: Springer.

Logger Pro. Available at http://www.vernier.com

Mathelitsch, L. \& Thaller, S. (2006). Fußball mit wissenschaftlichem Maß. Physik in unserer Zeit, 37(3), 122-125.

Mathelitsch, L. \& Thaller, S. (2008). Sport und Physik. Köln: Aulis Verlag.

Mathelitsch, L. \& Thaller, S. (2012). Olympische Rekorde. Physik in unserer Zeit, 43(4), 186-189.

Measure Dynamics. Available from http://www.phywe.de

de Mestre, N. (1990). The mathematics of projectiles in sport. Cambridge: Cambridge Univ. Press.

Physics Education. Available at http://iopscience.iop.org/0031-9120/

The Physics Teacher. Available at http://scitation.aip.org/content/aapt/journal/tpt

Physics World, July 2012. Available at http://physicsworld.com/

Spathopoulos, V. (2013). An introduction to the physics of sports. CreateSpace Independent Pub.

Thaller, S. (2003). Hochsprung auf dem Mond. Physik in unserer Zeit, 34(9), 87-89.

Tracker. Available at http://www.opensourcephysics.org/webdocs/Tools.cfm?t=Tracker

Trumper, R. (2006). Factors affecting junior high school students' interest in physics. Journal of Science Education and Technology, 15(1), 47-58.

Turner, W. A. \& Ellis, G. W. (1999). The Energetics of a Bouncing Ball. The Physics Teacher, 37, 496-496.

Viana. Available at http://viana.codeplex.com/ 
Wesson, J. (2002). The science of soccer. Oxon: Taylor \& Francis.

Wiese, J. (2002). Sports science. New York: John Wiley.

Wilson, D. G. (2004). Bicycling science. Cambridge: MIT Univ. Press.

LEOPOLD MATHELITSCH

Inst. Physics, Univ. Graz, Austria 